\title{
What is the risk of recurrent concussion in children and adolescents aged 5-18 years? A systematic review and meta-analysis
}

\author{
Jacqueline van lerssel (D) ,' Martin Osmond, 1,2,3 Jemila Hamid, 1,4 Margaret Sampson, ${ }^{1}$ \\ Roger Zemek 1,2,3
}

- Additional material is published online only. To view, please visit the journal online (http://dx.doi.org/10.1136/ bjsports-2020-102967).

${ }^{1}$ Children's Hospital of Eastern Ontario Research Institute, Ottawa, Ontario, Canada ${ }^{2}$ Emergency Department, Children's Hospital of Eastern Ontario Research Institute, Ottawa, Ontario, Canada ${ }^{3}$ Department of Pediatrics, University of Ottawa, Ottawa, Ontario, Canada

${ }^{4}$ Department of Mathematics and Statistics, University of Ottawa, Ottawa, Ontario, Canada

\section{Correspondence to}

Dr Jacqueline van lerssel, Children's Hospital of Eastern Ontario Research Institute, Ottawa, ON K1H 5B2, Canada; JMinnes@cheo.on.ca

Accepted 25 September 2020 Published Online First 19 October 2020

\begin{abstract}
Objective We aimed to examine the risk of concussion in children with a previous history of concussion.

Design Systematic review and meta-analysis. The primary outcome was number of children with and without a previous lifetime history of concussion who sustained a diagnosed concussion within each study period. Risk of bias was assessed using the Newcastle-Ottawa Scale. A random effects model was used to estimate a pooled risk ratio (RR) with corresponding $95 \% \mathrm{Cls}$; results were summarised in forest plots.

Data sources Four electronic databases (MEDLINE, Embase, CINAHL, SPORTDiscus) and selected reference lists were searched (PROSPERO registration No CRD42019135462).
\end{abstract}

Eligibility criteria Original English language peer-reviewed publications that compared concussion risk in children aged 5-18 years with and without a previous concussion history in which risk estimates were reported or able to be calculated. Results of 732 identified studies, 7 studies representing 23411 children (risk of bias range, 7-9; maximum possible score $=9$ ) were included for meta-analysis. Pooled risk of sustaining a concussion was more than three times greater in children with a previous concussion compared with those with no previous concussion (RR=3.64; $95 \% \mathrm{Cl}: 2.68$ to 4.96; $\left.p<0.0001 ; I^{2}=90.55 \%\right)$. Unreported sex-stratified data precluded direct comparison of concussion risk in male versus female athletes.

Conclusion Previously concussed children have four times the risk of sustaining a concussion compared with those with no previous concussion history. This should be a consideration for clinicians in return to sport decision-making. Future studies examining subsequent recurrent concussion in youth sports must consider sex differences.

\section{INTRODUCTION}

Widespread media attention on the impact of concussion in professional athletes has increased public concern about the sequelae and consequences of concussion. ${ }^{1}$ One to two million children under 18 years of age sustain a sport-related or recreation-related concussion in the USA every year. ${ }^{2}$ With over 30-45 million children participating in non-scholastic organised sports and 7.6 million adolescents participating in high-school athletics in the USA each year, youth represent the highest at-risk group for injury. ${ }^{34}$ The highest risk of sustaining a concussion is in collision sports such as rugby, ice hockey and American football, with incidence rates ranging from 0.5 to 4.2 concussions per 1000 athlete exposures. ${ }^{5-7}$ In sex-comparable sports, adolescent females may be at a greater risk of both sustaining a concussion ${ }^{8-10}$ and experiencing higher symptom burden, ${ }^{9} 11$ delayed symptom recovery ${ }^{12-14}$ and greater impairments in reaction time, processing speed and executive function ${ }^{910}$ compared with their male counterparts.

Compared with college and professional athletes, adolescents appear more vulnerable to concussion and take longer to recover due to neurological immaturity, thinner cortical skull bones and weaker supportive neck musculature. ${ }^{15-19}$ This is particularly concerning given the preventable nature of the injury in a critical period of neurological development. Furthermore, adolescents are more susceptible to the rare, but catastrophic, effects of second impact syndrome if they return to high-risk activities prematurely and sustain an exacerbation while still symptomatic from the initial concussion. ${ }^{20}$ Although the majority of concussion research involves college and professional athletes, existing return to sport (RTS) guidelines developed to reduce risk of subsequent injury assume recommendations apply equally to all ages. ${ }^{21}$ These guidelines allow return to physical activity (eg, walking, low-risk activities) early on, but require medical clearance for RTS (eg, unrestricted contact, competition, high-risk activities), only once the athletes are asymptomatic.

A previous history of concussion has been associated with an increased risk of any injury, ${ }^{22}$ risk of concus$\operatorname{sion}^{15} 22$ and risk of lower extremity musculoskeletal injury ${ }^{22-24}$ compared with those without a previous history of concussion. However, existing systematic reviews have either focused on adult populations (college football and hockey athletes, and military personnel), ${ }^{22}$ or did not present adult and paediatric results separately, ${ }^{15}$ limiting applicability to children. The primary objective of this systematic review was to examine the risk of concussion in children aged 5-18 years who had experienced a previous history of concussion compared with those with no previous lifetime history of concussion. Our secondary objective was to compare the risk of concussion in children with a previous history of concussion compared with no previous history of concussion, stratified by sex.

\section{METHODS}

Study identification: data sources and search strategy

This systematic review was registered a priori with PROSPERO (No CRD42019135462) at https:// www.crd.york.ac.uk/prospero/display_record.php? RecordID $=135462$ and was reported according to Preferred Reporting Items for Systematic Reviews and Meta-analyses (PRISMA) guidelines. ${ }^{25}$ We focused on risk of concussion exclusively as there 
was only one identified study that examined risk of (lower extremity) musculoskeletal injury following concussion. Four electronic databases were searched: MEDLINE including Epub Ahead of Print, In-Process \& Other Non-Indexed Citations (1946 to 21 May 2019) and Embase (1947 to 21 May 2019) using the Ovid interface. CINAHL and SPORTDiscus were searched 22 May 2019 using the EbscoHost interface (database dates not provided). Database-specific search terms for the concept of concussion were peer reviewed as part of an earlier systematic review. ${ }^{26}$ We updated our search in MEDLINE and Embase to include the term "exacerb".mp to be comprehensive and advance consistency of terminology adopted by the International Consensus Statement on Methods for Recording and Reporting of Epidemiological Data on Injury and Illness in Sport 2020 that was published after our original literature search. ${ }^{27}$ Search strategies are presented in online supplemental appendix 1. Searches were designed and conducted by a librarian experienced in systematic reviews, using a method designed to optimise term selection. ${ }^{28}$ References of included studies and relevant systematic reviews were manually searched and newly identified records were integrated into the set for screening.

\section{Study selection criteria}

Studies were included if they were original peer-reviewed English publications that reported risk of concussion in children aged 5-18 years with a previous history of concussion compared with those with no previous lifetime history of concussion and reported effect estimates routinely used as measures of injury risk (ie, risk ratio (RR), OR, HR, incidence rate ratio) ${ }^{29}$ that provided sufficient data for RRs to be calculated. As per consensus recommendations, a recurrent concussion was considered a subsequent injury 'to the same location and tissue as the index injury', where the 'index injury was healed/fully recovered'.(p375). ${ }^{27}$

Studies were excluded for the following reasons: (1) history of moderate-to-severe traumatic brain injury; (2) no documented, self-reported, or parent-reported head trauma; (3) non-sportsrelated injury; (4) evidence of structural injury or intracranial bleeding on neurodiagnostic imaging (if available); (5) head and orthopaedic injuries not reported separately; (6) child and adult data not reported separately in a mixed-age cohort; and (7) case reports, case series with $\mathrm{n}<10$, letters to the editor, abstracts or conference proceedings.

Duplicate records were removed online. Records were downloaded and imported into a Reference Manager database where a second deduplication process was undertaken, and then uploaded to InsightScope. Records were appraised against the inclusion criteria using a three-step approach. Two independent reviewers screened titles/abstracts of citations resulting from the search strategy to identify potentially relevant studies. In the event that no abstract was available, the full text was reviewed to ensure relevant studies were not missed. Full texts were then assessed for eligibility by two independent reviewers according to pre-established inclusion/exclusion criteria. When there was disagreement, the two reviewers reached consensus through collaborative discussion without the need for a third reviewer.

\section{Data extraction}

Two independent reviewers extracted the following information into a standardised data extraction form: author, year of publication, study design, country, length of exposure, study population (age, sex, sport, recruitment source), sample size, outcome measured and injury definition. We extracted data count and both unadjusted and adjusted measures of association with
95\% CIs. Effect estimates were reported based on describing increased risk of concussion. Where sex-stratified results were not published, we contacted the authors to obtain the raw data needed to make the calculations.

\section{Assessment of risk of bias}

Risk of bias was independently assessed by two reviewers using the Newcastle-Ottawa Scale (NOS). ${ }^{30}$ The NOS comprises eight criteria across three categories (maximum score nine stars) assessing selection criteria, comparability and exposure for case-control studies, and selection criteria, comparability and outcome for cohort studies. A high score indicates a low risk of bias. Discrepancies in scoring were resolved by discussion and consensus obtained between the two reviewers.

\section{Data synthesis and meta-analysis}

We performed a random effects meta-analysis to pool RRs across the studies and the results are summarised in a forest plot. When data (event count and sample size) were available, we calculated the RR for the studies before pooling, otherwise, we used the RR and its CI reported in the study. If both adjusted and unadjusted RRs were provided, we used the unadjusted values. When ORs were reported, we converted ORs to RR, where the control event rate was imputed from studies that provided data for the control group (no previous history of concussion). Statistical heterogeneity across studies was estimated using the $I^{2}$ statistic, with $25 \%, 50 \%$ and $75 \%$ considered low, medium and high heterogeneity, respectively. ${ }^{31}$ Analysis was performed using the metafor Package in the R Statistical Software. ${ }^{32}{ }^{33} \mathrm{An}$ $\mathrm{RR}>1$ indicated that the risk of subsequent injury is higher in children with a previous concussion. Statistical significance was determined at a level $\alpha=0.05$.

\section{Sensitivity analysis}

To address our secondary objective, we intended a priori to calculate sex-stratified risk estimates (RR (95\% CI)) to compare with our overall estimate of risk of concussion.

\section{RESULTS}

\section{Study identification}

The search strategy identified 911 studies, of which 732 titles and abstracts were screened (level one screening) after duplicates were removed. We assessed 34 full texts (level two screening) for eligibility and retained seven studies for meta-analysis (figure 1).

\section{Risk of bias assessment}

Based on the NOS, the risk of bias was low for all studies (range, $7-9$; maximum possible score $=9$, table 1 ). A single $(14 \%)$ study $^{34}$ described using structured injury data to ascertain risk exposure and $6(86 \%)$ studies ${ }^{34-39}$ demonstrated that participants were not concussed at the start of the study. Although several cohort studies adjusted for multiple potential confounders, including age, $5(71 \%)$ studies $^{37-40}$ did not adjust for previous history of mental health in their analysis. One retrospective cohort study ${ }^{36}$ lacked a systematic method for tracking concussion injuries.

\section{Characteristics of included studies}

The seven retained studies represented 23411 children. Six $(86 \%)$ were prospective cohort studies $(n=1359$ children with a previous concussion; $\mathrm{n}=11762$ children with no previous concussion), and $1(14 \%)$ was a retrospective cohort study ( $\mathrm{n}=1710$ children with a previous concussion; $\mathrm{n}=8580$ children with no previous concussion, table 2). The number of participants 


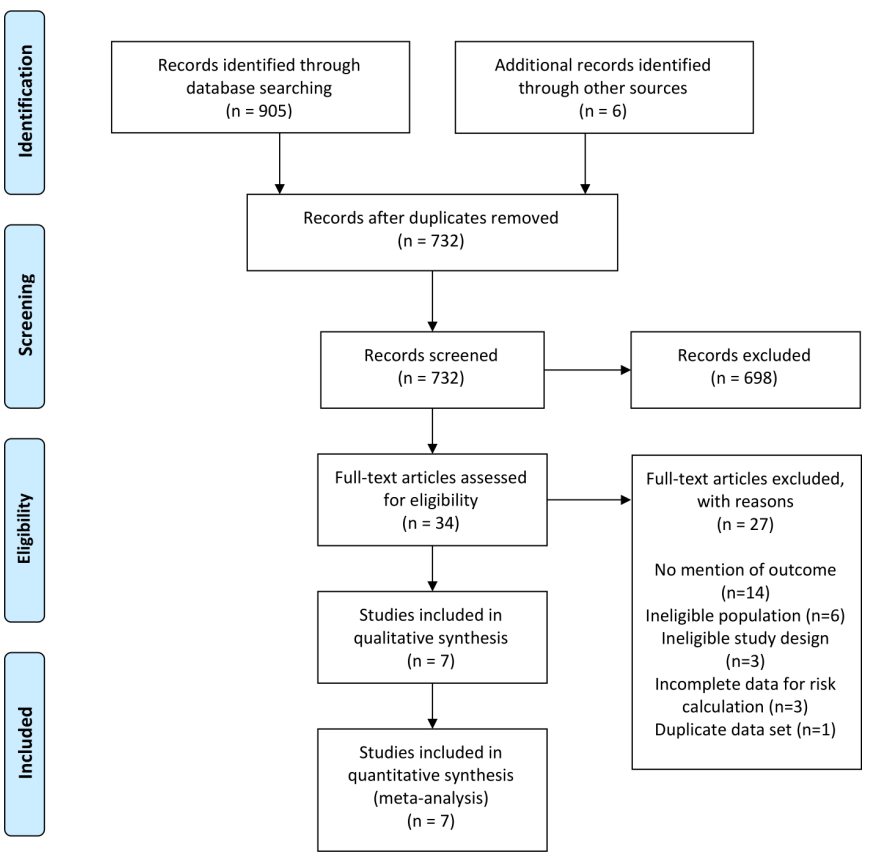

Figure 1 PRISMA 2009 flowchart. PRISMA, Preferred Reporting Items for Systematic Reviews and Meta-analyses

in a study ranged from $158^{37}$ to $10290 .^{36}$ Two (29\%) studies ${ }^{3740}$ included males only and 4 (57\%) studies 3353839 included at least $96 \%$ male athletes. None of the studies reported sex-stratified results. None of the authors provided the raw data after being contacted. Participants were recruited from American football $(n=3 ; 43 \%),{ }^{353740}$ middle and high-school sports $(n=1 ; 14 \%)^{36}$ and (hockey $(n=3 ; 43 \%) .{ }^{3438} 39$ Length of follow-up ranged from 1 to 2 sport seasons.

\section{Risk of concussion}

Overall pooled risk of sustaining a concussion was four times greater in children with a previous concussion compared with those with no history of concussion ( $\mathrm{RR}=3.64$; 95\% CI: 2.68 to $4.96 ; \mathrm{p}<0.0001 ; I^{2}=90.55 \%$, figure 2 ). All studies showed a statistically significant increase in risk of concussion among previously concussed athletes (RR (95\% CI)) ranging from 1.87 (1.19, $2.94)$ to $6.61(4.99,8.76)$. Despite high statistical heterogeneity
$\left(I^{2}=90.55 \%\right)$, we decided to proceed with performing a metaanalysis since six of the seven concussion studies utilised the same study design (ie, prospective cohort studies), applied similar validated diagnostic criteria for concussion (ie, Fourth International Consensus Conference on Concussion in Sport or American Academy of Neurology), ${ }^{41} 42$ assessed primarily American Academy of Pediatrics defined contact or collisions sports ${ }^{43}$ shown to have a high risk of concussion (eg, football, hockey), ${ }^{67}$ and followed children for one or two seasons.

Based on the Grading of Recommendations, Assessment, Development, and Evaluations (GRADE) framework, ${ }^{44}$ there is a low level of certainty that the true risk of concussion is close to the estimated effect. However, several studies included large sample sizes with large numbers of events (concussions) and included studies were deemed to have a low risk of bias with similar point estimates and overlapping 95\% CIs, which demonstrates consistency of findings. Confidence in the evidence may likewise be increased as Tsushima et $a l^{36}$ reported a greater risk of recurrent concussion following two previous concussions than after a single concussion, suggesting there may be a dose response.

\section{Risk of concussion, stratified by sex}

Sex-specific results were not reported in any of the studies, and authors were unable to provide the requested raw data, therefore we performed a post-hoc meta-analysis consisting of studies with $96 \%$ or more male participants. 35 37-40

In a sensitivity analysis of a predominantly male population of youth athletes with and without a previous history of concussion, the point estimate for risk of concussion was lower $(\mathrm{RR}=2.98$; 95\% CI: 1.95 to $4.55 ; \mathrm{p}<0.0001 ; I^{2}=77.76 \%$, figure 3 ) when compared with our overall estimate ( $\mathrm{RR}=3.64 ; 95 \% \mathrm{CI}: 2.68$ to $\left.4.96 ; \mathrm{p}<0.0001 ; I^{2}=90.55 \%\right)$. However, the considerable overlap in the CIs with our overall estimate limits interpretation of the findings regarding risk differences. Furthermore, although the sensitivity analysis lowered the statistical heterogeneity of the pooled estimate, it still remained high.

\section{DISCUSSION}

This systematic review of high-quality studies, that included more than 3000 children under 18 years of age with a previous concussion and more than 20000 children with no previous concussion, demonstrated that children who RTS following

Table 1 Risk of bias for cohort studies as assessed with the NOS

\begin{tabular}{|c|c|c|c|c|c|c|c|}
\hline & $\begin{array}{l}\text { Zemper } \\
2003^{40}\end{array}$ & $\begin{array}{l}\text { Kontos et al, } \\
2006^{37}\end{array}$ & $\begin{array}{l}\text { Chrisman et al, } \\
2019^{35}\end{array}$ & $\begin{array}{l}\text { Tsushima et al, } \\
2019^{36}\end{array}$ & $\begin{array}{l}\text { Emery et al, } \\
2010^{38}\end{array}$ & $\begin{array}{l}\text { Emery et al, } \\
2011^{39}\end{array}$ & $\begin{array}{l}\text { Black et al, } \\
2016^{34}\end{array}$ \\
\hline \multicolumn{8}{|l|}{ Selection } \\
\hline Representativeness of the exposed cohort & $*$ & $*$ & * & * & * & * & * \\
\hline Selection of the non-exposed cohort & $*$ & $*$ & $*$ & $*$ & * & * & * \\
\hline Ascertainment of exposure & $*$ & $*$ & & & * & * & $*$ \\
\hline Demonstration outcome not present at start & & $*$ & $*$ & * & * & * & * \\
\hline \multicolumn{8}{|l|}{ Comparability } \\
\hline Comparability of cohort on basis of design or analysis & * & $* *$ & $* *$ & ** & $* *$ & $* *$ & $* *$ \\
\hline \multicolumn{8}{|l|}{ Outcome } \\
\hline Assessment of outcome & * & * & $*$ & $*$ & $*$ & * & $*$ \\
\hline Was follow-up long enough for outcomes to occur? & $*$ & $*$ & $*$ & $*$ & $*$ & $*$ & $*$ \\
\hline Adequacy of follow-up cohorts & * & * & * & & * & * & * \\
\hline Total stars & 7 & 9 & 8 & 7 & 9 & 9 & 9 \\
\hline
\end{tabular}

Maximum total score is 9. A study can be awarded a maximum of one star for each numbered item within the selection and outcome categories. A maximum of two stars can be given for comparability. ${ }^{30} \mathrm{~A}$ high score indicates a low risk of bias.

NOS, Newcastle-Ottawa Scale. 
Table 2 Study characteristics

\begin{tabular}{|c|c|c|c|c|c|c|c|c|c|}
\hline Study & $\begin{array}{l}\text { Study } \\
\text { design }\end{array}$ & $\begin{array}{l}\text { Length of } \\
\text { exposure }\end{array}$ & Study population & $\begin{array}{l}\text { Age } \\
\text { (years) }\end{array}$ & $\begin{array}{l}\text { Athletes with } \\
\text { previous } \\
\text { concussion } \\
\text { (No) }\end{array}$ & $\begin{array}{l}\text { Athletes with } \\
\text { no previous } \\
\text { concussion } \\
\text { (No) }\end{array}$ & $\begin{array}{l}\text { Concussion } \\
\text { definition }\end{array}$ & Adjustment factors & $\begin{array}{l}\text { Effect estimate } \\
(95 \% \mathrm{Cl})\end{array}$ \\
\hline Zemper, $2003^{40}$ & PC & $\begin{array}{l}\text { Two football } \\
\text { seasons }\end{array}$ & $\begin{array}{l}\text { National high } \\
\text { school football } \\
\text { players (AIMS) } \\
\text { (n=7197 player- } \\
\text { seasons; male 7197) }\end{array}$ & Not identified & 296 & 6901 & AAN 1997 & N/A & RR 6.61 (5.0 to 8.8) \\
\hline $\begin{array}{l}\text { Chrisman et al, } \\
2019^{35}\end{array}$ & PC & $\begin{array}{l}2 \times 10 \text { week } \\
\text { football } \\
\text { seasons }\end{array}$ & $\begin{array}{l}\text { Seattle youth } \\
\text { football league } \\
\text { ( } n=863 ; \text { male 854) }\end{array}$ & $\begin{array}{l}5-7(n=96) \\
8-10(n=300) \\
11-12(n=311) \\
13-14(156)\end{array}$ & 115 & 748 & CISG 2012 & $\begin{array}{l}\text { Age, sex, parent } \\
\text { education, ethnicity, } \\
\text { race, attention } \\
\text { problems, headaches, } \\
\text { years playing football }\end{array}$ & OR 2.24 (1.05 to 4.75$)$ \\
\hline $\begin{array}{l}\text { Emery et al, } \\
2010^{38}\end{array}$ & PC & $\begin{array}{l}\text { One ice- } \\
\text { hockey season }\end{array}$ & $\begin{array}{l}\text { Alberta and Quebec } \\
\text { Pee Wee ice-hockey } \\
\text { players } \\
(\mathrm{n}=2154 \text {; male } \\
2117) \\
\text { Sex missing data } \\
\mathrm{n}=4\end{array}$ & $\begin{array}{l}\text { Pee Wee } \\
11-12\end{array}$ & 328 & 1786 & CISG 2004 & $\begin{array}{l}\text { Year of play, player } \\
\text { size, level of play, } \\
\text { position, body } \\
\text { checking attitude }\end{array}$ & IRR 2.14 (1.28 to 3.55$)$ \\
\hline $\begin{array}{l}\text { Emery et al, } \\
2011^{39}\end{array}$ & PC & $\begin{array}{l}\text { One ice- } \\
\text { hockey season }\end{array}$ & $\begin{array}{l}\text { Alberta and Quebec } \\
\text { Bantam ice-hockey } \\
\text { players } \\
(\mathrm{n}=1971 \text {; male } \\
\text { 1956) }\end{array}$ & $\begin{array}{l}\text { Bantam } \\
13-14\end{array}$ & 453 & 1480 & CISG 2004 & $\begin{array}{l}\text { Clustering by team, } \\
\text { year of play, player } \\
\text { size, level of play, } \\
\text { player position, body } \\
\text { checking attitude }\end{array}$ & IRR 1.87 (1.19 to 2.94$)$ \\
\hline $\begin{array}{l}\text { Black et al, } \\
2016^{34}\end{array}$ & PC & $\begin{array}{l}\text { One ice- } \\
\text { hockey season }\end{array}$ & $\begin{array}{l}\text { Alberta }(n=581 ; \\
\text { male } 553) \text { and } \\
\text { Ontario }(n=280 ; \\
\text { male 274) Pee Wee } \\
\text { non-elite ice hockey } \\
\text { players; missing } \\
\text { data } n=10\end{array}$ & Pee Wee 11-12 & 138 & 718 & CISG 2012 & $\begin{array}{l}\text { Clustering by team, } \\
\text { exposure hours, } \\
\text { year of play, level of } \\
\text { play, position, body } \\
\text { checking attitude }\end{array}$ & IRR 3.16 (1.86 to 5.39 ) \\
\hline
\end{tabular}

*Per previous number of concussions.

AAN, American Academy of Neurology; ADD/ADHD, attention-deficit disorder/attention-deficit hyperactivity disorder; AIMS, Athletic Injury Monitoring System; BMI, body mass index; CHOP, Children's Hospital of Philadelphia; CISG, Concussion in Sport Group; IRR, incidence rate ratio; PC, prospective cohort; RC, retrospective cohort; RR, rate ratio.

concussion are at nearly four times greater risk of sustaining a concussion relative to those with no previous concussion.

These findings extend previous systematic reviews that concluded previous concussion is a risk factor for sustaining a concussion across a wide range of ages and populations. ${ }^{1522}$ In a predominantly adult population that included athletes and military personnel, the pooled odds of sustaining a concussion were 3.73 times higher in those with a previous concussion. A single narrative review of sport-related concussions concluded there was a high level of certainty that previous concussion increases concussion risk, but no pooled estimate was calculated. ${ }^{15}$ Although the estimated concussion risk was similar in our study, youth athletes have a higher overall incidence of concussion compared with college athletes. In a large prospective cohort study ${ }^{45}$ with over 1000 reported concussions, high-school football players had twice the rate of concussions per 1000 total athlete exposure as Division I college players (1.03 vs 0.49 ).

Possible factors to explore in future research to study this difference may include rule changes, equipment standards, concussion assessment techniques, reduced practice contact and awareness of concussion protocols. Furthermore, the incidence of recurrent concussion is likely underestimated, as approximately $50 \%$ of all concussions in youth may be unreported as a result of fear of being removed from a game, not wanting to let down teammates, lack of knowledge around common concussion signs and symptoms or not thinking they were serious enough to seek medical attention. ${ }^{46} 47$

Our data suggesting a threefold to fourfold greater risk of concussion among previously concussed children may be an underestimate. Some previously concussed children may not have returned to their sport within the study periods due to persistent symptoms and these athletes would be more vulnerable to repetitive head trauma on RTS, especially if physiological recovery is delayed beyond recovery of self-reported symptoms. ${ }^{48}$

Increased cerebral vulnerability may lead to either an exacerbation of symptoms from the index concussion or a reinjury. This is concerning, as recurrent concussions in adolescents have been associated with a greater severity of on-field signs and symptoms (loss of consciousness, anterograde amnesia, confusion), ${ }^{49}$ prolonged symptom recovery ${ }^{14} 50$ and higher baseline symptom reporting, ${ }^{51-54}$ and dynamic motor function deficits. ${ }^{55}$ It is unclear whether this represents a cumulative effect of multiple concussions, incomplete physiological recovery or neurological predisposition to injury. The high annual incidence of paediatric concussions sustained yearly translates into preventable morbidity for a substantial number of youths. Our 


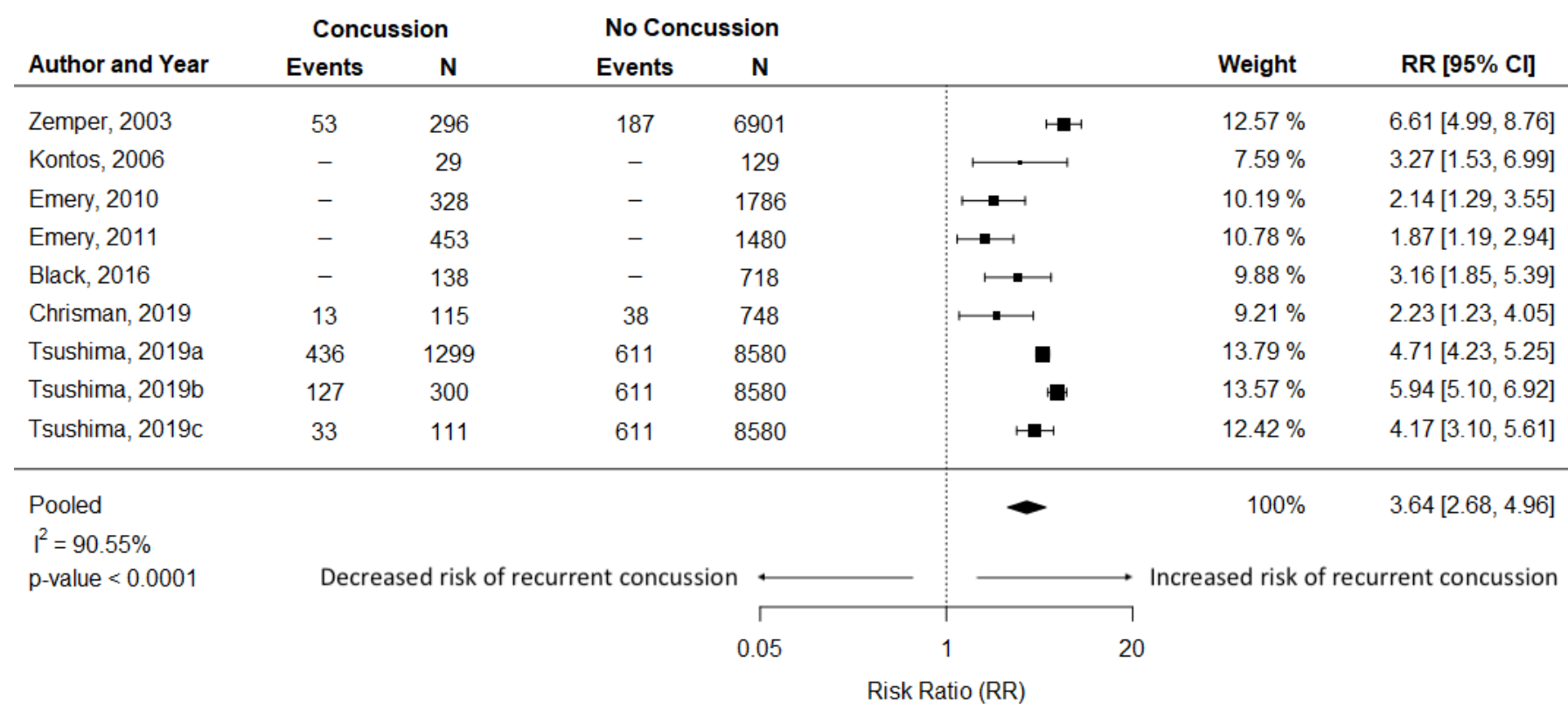

Figure 2 Forest plot of RR of recurrent concussion following index concussion for all included studies. The $R R(95 \% \mathrm{Cl})$ from individual studies and the pooled data are shown. Box size represents the relative weight each study contributes to the pooled estimate. RR $>1$ indicates greater risk of recurrent concussion for children with a previous lifetime history of concussion compared with those without a previous concussion. Tsushima 2019a presents the RR for youth with one previous concussion; Tsushima 2019b presents the RR for youth with two previous concussions; and Tsushima 2019 c presents the RR for youth with three plus previous concussions. RR, risk ratio.

findings suggest children have an increased vulnerability to recurrent concussion. We highlight the importance of establishing age-specific timelines for progression through established RTS medical clearance protocols to mitigate the risk.

\section{Sex-specific differences}

Understanding sex-specific differences in concussion risk was an important secondary objective of this study. It is noteworthy that few studies in this review included a meaningful number of females. Regrettably, none of the included studies provided sex-specific concussion rates, therefore we cannot determine whether differences in concussion risk exist between previously concussed male and female athletes compared with same-sex athletes with no previous concussion. Although we calculated a lower point estimate of concussion risk in a predominantly male population, further research is needed to determine whether sexspecific differences account for a variance in the RR given the significant overlap in CIs and high percentage of males (81\%) in the overall population. Similar to previous reviews ${ }^{7} 5657$ exploring a wide range of outcomes associated with concussion, a general lack of reported differences in risk between males and females precluded inference and represents a critical gap in the literature.

Possible sex differences that might account for these findings include lower injury thresholds, ${ }^{58}$ neck strength,${ }^{59}$ injury biomechanics, ${ }^{60}$ women report more symptoms ${ }^{1161}$ and hormones. ${ }^{5862}$

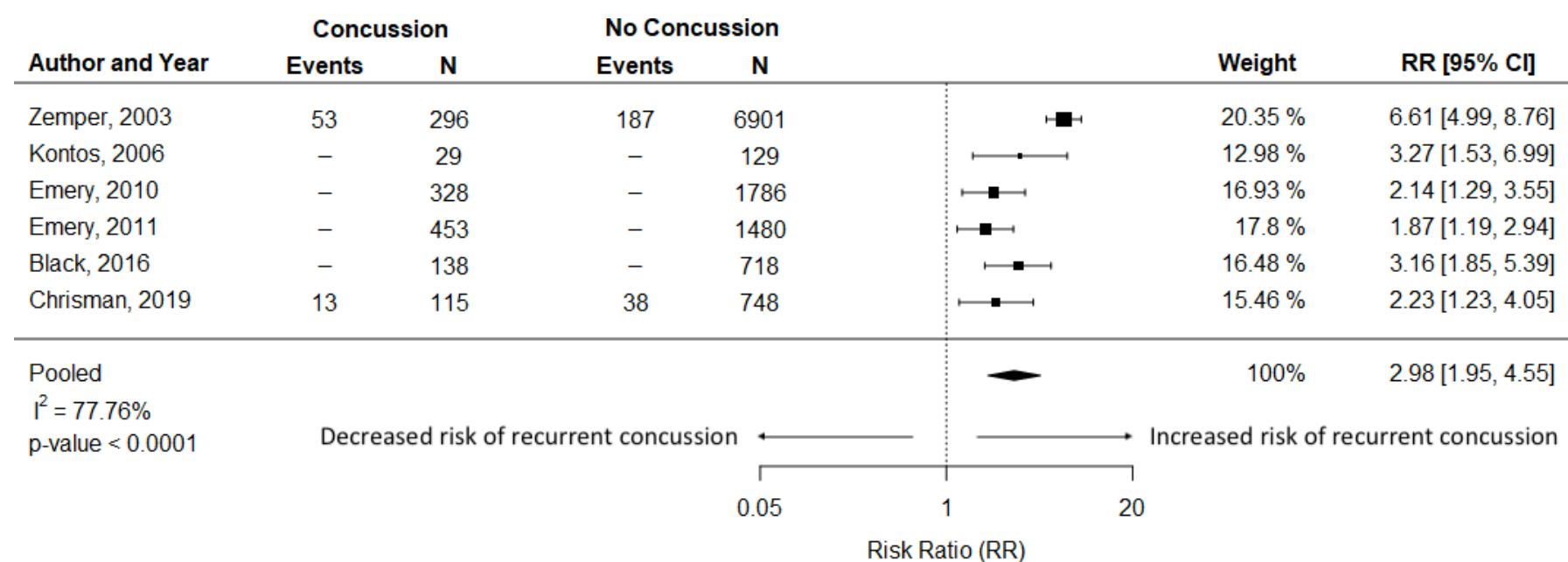

Figure 3 Forest plot of RR of recurrent concussion following index concussion for predominantly male studies ( $\geq 96 \%$ male). The RR (95\% Cl) from individual studies and the pooled data are shown. Box size represents the relative weight each study contributes to the pooled estimate. RR $>1$ indicates greater risk of recurrent concussion for children with a previous lifetime history of concussion compared with those without a previous concussion. RR, risk ratio. 
Given high levels of female sport participation and a 6.3-fold increase in rate of overall child and adolescent concussion from 2003 to $2013,{ }^{63}$ large prospective cohort studies reporting point estimates and associated 95\% CIs comparing males and females with a previous concussion to non-concussed counterparts are needed to understand the effect of sex on concussion risk.

\section{Explanations for increased susceptibility to concussion in youth}

Although evidence suggests that a previous concussion increases the risk of concussion, our understanding of the underlying physiology behind this continues to evolve. Possible explanations include residual physiological effects from the primary concussion, microstructural injury, structural factors, genetic predisposition, impaired neuromotor control and sensorimotor deficits. ${ }^{7} 172455$ 64-71 A neurometabolic cascade of events that include ionic shifts, metabolic energy deficits, cytoskeletal damage, axonal dysfunction, altered neurotransmission, altered blood flow and inflammation has been associated with increased vulnerability to recurrent concussion. ${ }^{66}$ 67 Animal models and human studies suggest allowing increased time for recovery following concussion reduces metabolic vulnerability and severity of neurocognitive dysfunction. ${ }^{667}$ While this aligns with current clinical guidelines for immediate removal from play following a concussion and a graduated exercise strategy to allow for physiologic recovery, age-specific and sex-specific timelines for safe RTS are still unclear.

Impaired neuromotor control and cognitive processing have also been cited as potential risk factors ${ }^{23}$ with possible cumulative effects. ${ }^{55}$ Lingering deficits may impair an athlete's ability to simultaneously integrate cognitive demands with postural strategies required to safely react to their environment during sport. ${ }^{55}$ Preliminary evidence that concussion risk can be reduced with a neuromuscular training programme offers promise as a potential prevention strategy. ${ }^{71}$ Additionally, deficits in cervical spine proprioception, vestibular-ocular function and visual systems following concussion can reduce postural stability. ${ }^{6465}$ Persistent impairments in dynamic postural stability months following concussion may result in altered movement strategies that increase recurrent concussion risk. ${ }^{24}$ Individualised cervical and vestibular physiotherapy have been shown to decrease time to RTS medical clearance following concussion; further research is needed to determine any protective effect against recurrent concussion. $^{70}$

This study has several strengths that bolster the validity of our findings. To our knowledge, this is the first systematic review of risk of concussion following paediatric concussion. Multiple databases were searched along with reference lists of relevant studies. Study selection and data extraction were done independently. Additionally, all included studies were rated as high quality of evidence and study populations were large for most studies. All studies show substantial effects with evidence of some dose-response relationship.

These results should be considered in the context of the following limitations. First, as with all systemic reviews, the risk of publication bias must be considered, which may have overestimated the estimated risk of concussion. Second, there was significant heterogeneity between studies when calculating our pooled estimate. Some of the heterogeneity may be explained by sex differences, as heterogeneity $\left(I^{2}\right)$ fell when we calculated the risk estimate for male-dominant studies. We also calculated an unadjusted risk estimate due to wide variations between studies in controlling for relevant covariates, which may explain some
What is already known?

- Incidence of youth diagnosed with concussion has quadrupled in the last decade.

- College athletes with a history of concussion are at an increased risk of subsequent injury, including recurrent concussion and lower extremity injury.

What are the new findings?

- Having a lifetime history of concussion is associated with a four times greater risk of concussion in children.

- A paucity of evidence on risk of concussion in girls aged 5-18 years is a major shortcoming in existing research.

of the heterogeneity. ${ }^{72}$ For example, Kontos et $a l^{37}$ controlled for learning disabilities and attention-deficit/hyperactivity disorder in the study design, whereas Emery et $a^{38} 39$ and Black et $a l^{34}$ controlled for year of play, player size, level of play and body checking attitude in their analysis; Tsushima et $a l^{3536}$ and Chrisman controlled for sex. Age of participants may also have contributed to heterogeneity, as those studies that included children aged 5-12 years had a lower RR (range, 2.14-2.23) than three out of four studies that included adolescents aged 13-18 (range, 3.27-6.61). The heterogeneity may also be associated with calculating the unadjusted RR using count data in studies where either ORs ${ }^{35} 37$ or incidence rate ratios ${ }^{3438} 39$ were reported. However, these studies were sufficiently similar in design, diagnostic criteria, sport type and follow-up period to be reasonably confident in our findings. Third, selection bias may have been introduced due to the small number of female athletes ( $n=4491 ; 19 \%$ of total sample) included in the overall meta-analysis, almost exclusively from the only retrospective study ( $n=4396 ; 98 \%$ of total females), thereby limiting the generalisability of the results to females. Furthermore, our sensitivity analysis precluded definitive conclusions regarding sexspecific differences in concussion risk. Fourth, risk of concussion may differ based on time since previous concussion or clinical markers of recovery, however we were unable to study that as several studies failed to report clearly defined RTS clearance criteria or time interval between first and recurrent concussions. Fifth, measurement bias may have been introduced related to concussion exposure, potentially leading to substantial bias in the risk estimate. Despite rigorous injury surveillance systems used across all studies, differences in type of athlete exposures were not consistently reported or included in statistical modelling, despite the higher risk of concussion in competition than in practice. ${ }^{73}$ Sex-specific differences in concussion rates during games versus practices should be considered in future research. Similarly, although athletes with a suspected concussion were assessed using a standard definition of concussion, the lack of objective diagnostic biomarker raises the possibility of misclassification or non-detection.

Finally, given the small number of studies found, we could not further explore important facets of this topic including sex differences (males dominated), differences across sport, geography and culture (most studies were done in the North American context and focused on football and ice hockey) or age groups (only one study examined effects in children under 10, who may be experiencing rapid neurodevelopmental changes), making it unclear whether our results are generalisable. Despite 
these limitations, statistical agreement across all studies based on individual point estimates and 95\% CIs (although varied in size) and high quality of included studies support our finding of increased risk of concussion in youth with a previous concussion.

\section{Clinical and research relevance}

Clinicians must consider previous concussion history when making RTS clearance decisions and educate families regarding the increased risk of concussion in youth. Although timelines for safe RTS following paediatric concussion have not yet been determined, current international guidelines recommend that once athletes are symptom-free, they should complete a six-stage graded exercise strategy to allow for fuller recovery before returning to at-risk activities. ${ }^{21}$ Efficacy of this strategy in reducing recurrent concussions has not been investigated. As per expert consensus, medical clearance decisions rely primarily on symptom reporting, which has been shown to resolve before neurocognitive status and functional balance. This highlights the need for further research to identify modifiable risk factors that can be assessed, mediated through intervention and required for medical clearance. There is also a strong need to identify objective biomarkers of recovery and their role in predicting recurrent concussion. Identification of ongoing functional disturbances and microstructural injury within advanced neuroimaging and fluid biomarker research appears promising; however, clinical application requires further validation before implementation in concussion management. ${ }^{74}$ In the meantime, clinicians should consider managing children with concussion more conservatively than adults as the increased risk of concussion is even more concerning given children's previously established potentially increased vulnerability to concussion, potentially longer recovery times and potential for adverse long-term consequences during a sensitive period of neurodevelopment growth. ${ }^{15-19}$ Since current management of paediatric concussion is based on evidence from animal and adult human research, future consensus guidelines need to consider evidence-based age-specific and sex-specific recommendations for RTS following paediatric concussion.

\section{CONCLUSION}

Children with a previous concussion are at a greater risk of concussion after returning to sport compared with children with no history of concussion. Understanding the cause and timeline of increased risk is essential in order to inform age-specific RTS guidelines. Future studies examining concussion risk in youth sports must consider sex-specific differences. Further research is needed to determine objective markers of physiological recovery, identify clinical risk factors for recurrent concussion in children, evaluate evidence-based prevention strategies to mitigate concussion risk, inform medical clearance decision-making following concussion and reduce the long-term sequelae of multiple concussions.

Acknowledgements We thank Katie O'Hearn, Msc, (Children's Hospital of Eastern Ontario Research Institute) for methodological assistance.

Contributors Jvl, MS and RZ contributed to the conception or design of the work. $\mathrm{Jvl}, \mathrm{MO}$ and $\mathrm{JH}$ collected the data. Jvl, $\mathrm{MO}$ and $\mathrm{JH}$ contributed to the analysis and interpretation of the work. Jvl drafted the manuscript. MO, MS, JH and RZ critically reviewed the manuscript for important intellectual content. All authors approve of the final version and agree to be responsible for all aspects of the work ensuring accuracy and integrity.

Funding The authors have not declared a specific grant for this research from any funding agency in the public, commercial or not-for-profit sectors.

Competing interests Jvl reported receiving speaking honoraria and travel expenses for presentations at scientific meetings; and is founder and an instructor for
R2P Concussion Management. RZ reported being a coapplicant on a competitively funded grant administered by the National Football League through the independent scientific advisory board to fund a prospective concussion study with the goal of preventing concussions; he does not personally receive any funding for this work; his institution receives the operating funds to conduct the research; he has received honoraria from Parachute Canada (a Canadian non-profit for injury prevention) for his role on the Concussion Expert Advisory board.

Patient consent for publication Not required.

Provenance and peer review Not commissioned; externally peer reviewed.

Supplemental material This content has been supplied by the author(s) It has not been vetted by BMJ Publishing Group Limited (BMJ) and may not have been peer-reviewed. Any opinions or recommendations discussed are solely those of the author(s) and are not endorsed by BMJ. BMJ disclaims all liability and responsibility arising from any reliance placed on the content. Where the content includes any translated material, BMJ does not warrant the accuracy and reliability of the translations (including but not limited to local regulations, clinical guidelines, terminology, drug names and drug dosages), and is not responsible for any error and/or omissions arising from translation and adaptation or otherwise

\section{ORCID iD}

Jacqueline van lerssel http://orcid.org/0000-0001-5519-8526

\section{REFERENCES}

1 Merz ZC, Van Patten R, Lace J. Current public knowledge pertaining to traumatic brain injury: influence of demographic factors, social trends, and sport concussion experience on the understanding of traumatic brain injury sequelae. Arch Clin Neuropsychol 2017;32:155-67.

2 Bryan MA, Rowhani-Rahbar A, Comstock RD, et al. Sports- and recreation-related concussions in US youth. Pediatrics 2016;138. doi:10.1542/peds.2015-4635. [Epub ahead of print: 20 Jun 2016].

3 Gioia GA, Schneider JC, Vaughan CG, et al. Which symptom assessments and approaches are uniquely appropriate for paediatric concussion? Br J Sports Med 2009:43:i13-22.

4 National Federation of State High School Associations. 2009-2010 high school athletics participation survey, 2010.

5 Sarmiento K, Thomas KE, Daugherty J, et al. Emergency department visits for sportsand recreation-related traumatic brain injuries among children — United States, 2010-2016. MMWR Morb Mortal Wkly Rep 2019;68:237-42.

6 Kerr ZY, Chandran A, Nedimyer AK, et al. Concussion incidence and trends in 20 high school sports. Pediatrics 2019;144. doi:10.1542/peds.2019-2180. [Epub ahead of print: 15 Oct 2019].

7 Pfister T, Pfister K, Hagel B, et al. The incidence of concussion in youth sports: a systematic review and meta-analysis. Br J Sports Med 2016;50:292-7.

8 Bretzin AC, Covassin T, Fox ME, et al. Sex differences in the clinical incidence of concussions, missed school days, and time loss in high school Student-Athletes: Part 1. Am J Sports Med 2018;46:2263-9.

9 Broshek DK, Kaushik T, Freeman JR, et al. Sex differences in outcome following sportsrelated concussion. J Neurosurg 2005;102:856-63.

10 Dick RW. Is there a gender difference in concussion incidence and outcomes? $\mathrm{Br} J$ Sports Med 2009;43:i46-50.

11 Brown DA, Elsass JA, Miller AJ, et al. Differences in symptom reporting between males and females at baseline and after a sports-related concussion: a systematic review and meta-analysis. Sports Med 2015;45:1027-40.

12 Bock S, Grim R, Barron TF, et al. Factors associated with delayed recovery in athletes with concussion treated at a pediatric neurology concussion clinic. Childs Nerv Syst 2015:31:2111-6.

13 Eisenberg MA, Andrea J, Meehan W, et al. Time interval between concussions and symptom duration. Pediatrics 2013;132:8-17.

14 Zemek R, Barrowman N, Freedman SB, et al. Clinical risk score for persistent Postconcussion symptoms among children with acute concussion in the ED. JAMA 2016;315:1014-25.

15 Abrahams S, Fie SM, Patricios J, et al. Risk factors for sports concussion: an evidencebased systematic review. Br J Sports Med 2014;48:91-7

16 Buzzini SRR, Guskiewicz KM. Sport-related concussion in the young athlete. Curr Opin Pediatr 2006;18:376-82.

17 Karlin AM. Concussion in the pediatric and adolescent population: "different population, different concerns". Pm R 2011;3:S369-79.

$18 \operatorname{Sim}$ A, Terryberry-Spohr L, Wilson KR. Prolonged recovery of memory functioning after mild traumatic brain injury in adolescent athletes. J Neurosurg 2008;108:511-6.

19 Davis GA, Anderson V, Babl FE, et al. What is the difference in concussion management in children as compared with adults? A systematic review. Br J Sports Med 2017;51:949-57.

20 McLendon LA, Kralik SF, Grayson PA, et al. The controversial second impact syndrome: a review of the literature. Pediatr Neurol 2016;62:9-17. 
21 McCrory P, Meeuwisse W, Dvořák J, et al. Consensus statement on concussion in sport-the $5^{\text {th }}$ international conference on concussion in sport held in Berlin, October 2016. Br J Sports Med 2017;51:838-47.

22 Reneker JC, Babl R, Flowers MM. History of concussion and risk of subsequent injury in athletes and service members: a systematic review and meta-analysis. Musculoskelet Sci Pract 2019;42:173-85.

23 McPherson AL, Nagai T, Webster KE, et al. Musculoskeletal injury risk after sportrelated concussion: a systematic review and meta-analysis. Am J Sports Med 2019;47:1754-62.

24 Brooks MA, Peterson K, Biese K, et al. Concussion increases odds of sustaining a lower extremity musculoskeletal injury after return to play among collegiate athletes. Am J Sports Med 2016;44:742-7.

25 Moher D, Liberati A, Tetzlaff J, et al. Preferred reporting items for systematic reviews and meta-analyses: the PRISMA statement. PLoS Med 2009;6:e1000097.

26 Ontario Neurotrauma Foundation. Guidelines for diagnosing and managing pediatric concussion, 2014. Available: http://concussionsontario.org/resources/guidelines-forpediatric-concussion/.

27 Bahr R, Clarsen B, Derman W, et al. International Olympic Committee consensus statement: methods for recording and reporting of epidemiological data on injury and illness in sport 2020 (including STROBE extension for sport injury and illness surveillance (STROBE-SIIS)). Br J Sports Med 2020;54:372-89.

28 Bramer WM, de Jonge GB, Rethlefsen ML, et al. A systematic approach to searching: an efficient and complete method to develop literature searches. J Med Libr Assoc 2018;106:531-41.

29 Hopkins WG, Marshall SW, Quarrie KL, et al. Risk factors and risk statistics for sports injuries. Clin J Sport Med 2007;17:208-10.

30 Wells G, Shea B, O'Connell D, et al. The Newcastle-Ottawa scale (NOS) for assessing the quality of nonrandomised studies in meta-analyses. Available: http://www.ohri.ca/ programs/clinical_epidemiology/oxford.asp [Accessed 23 Aug 2019].

31 Higgins JPT, Thompson SG, Deeks JJ, et al. Measuring inconsistency in meta-analyses. BMJ 2003;327:557-60.

32 R Core Team. R: a language and environment for statistical computing, 2020. Available: http://www.r-project.org/

33 Viechtbauer W. Conducting Meta-analyses in $R$ with the metafor Package. J Stat Softw 2010;36.

34 Black AM, Macpherson AK, Hagel BE, et al. Policy change eliminating body checking in non-elite ice hockey leads to a threefold reduction in injury and concussion risk in 11- and 12-year-old players. Br J Sports Med 2016;50:55-61.

35 Chrisman SPD, Lowry S, Herring SA, et al. Concussion incidence, duration, and return to school and sport in 5- to 14-year-old American football athletes. J Pediatr 2019;207:176-84

36 Tsushima WT, Siu AM, Ahn HJ, et al. Incidence and risk of concussions in youth athletes: comparisons of age, sex, concussion history, sport, and football position. Arch Clin Neuropsychol 2019;34:60-9.

37 Kontos AP, Elbin RJ, Michael III. Aerobic fitness and concussion outcomes in high school football. In: Foundations of sport-related brain injuries. Boston, MA: Springer, 2006: 315-39.

38 Emery CA, Kang J, Shrier I, et al. Risk of injury associated with body checking among youth ice hockey players. JAMA 2010;303:2265-72.

39 Emery C, Kang J, Shrier I, et al. Risk of injury associated with bodychecking experience among youth hockey players. Can Med Assoc J 2011;183:1249-56.

40 Zemper ED. Two-year prospective study of relative risk of a second cerebral concussion. Am J Phys Med Rehabil 2003;82:653-9.

41 McCrory P, Meeuwisse WH, Aubry M, et al. Consensus statement on concussion in sport: the 4th International Conference on concussion in sport held in Zurich, November 2012. Br J Sports Med 2013;47:250-8.

42 Practice parameter: the management of concussion in sports (summary statement). Neurology 1997;48:581-5.

43 Dyment $\mathrm{P}$, Goldberg B, Haefele $\mathrm{S}$, et al. Recommendations for participation in competitive sports. Pediatrics 1988;81:737-9.

44 Siemieniuk R, Guyatt G. What is grade? BMJ best practice. Available: https:// bestpractice.bmj.com/info/toolkit/learn-ebm/what-is-grade/ [Accessed 17 Jun 2020].

45 Guskiewicz KM, Weaver NL, Padua DA, et al. Epidemiology of concussion in collegiate and high school football players. Am J Sports Med 2000;28:643-50.

46 McCrea M, Hammeke T, Olsen G, et al. Unreported concussion in high school football players: implications for prevention. Clin J Sport Med 2004;14:13-17.
47 Williamson IJS, Goodman D. Converging evidence for the under-reporting of concussions in youth ice hockey. Br J Sports Med 2006;40:128-32.

48 Kamins J, Bigler $E$, Covassin T, et al. What is the physiological time to recovery after concussion? A systematic review. Br J Sports Med 2017:51:935-40.

49 Collins MW, Lovell MR, Iverson GL, et al. Cumulative effects of concussion in high school athletes. Neurosurgery 2002;51:1175-81.

50 Corwin DJ, Zonfrillo MR, Master CL, et al. Characteristics of prolonged concussion recovery in a pediatric subspecialty referral population. J Pediatr 2014;165:1207-15.

51 Mannix R, Iverson GL, Maxwell B, et al. Multiple prior concussions are associated with symptoms in high school athletes. Ann Clin Trans/ Neurol 2014;1:433-8.

52 Brooks BL, McKay CD, Mrazik M, et al. Subjective, but not objective, lingering effects of multiple past concussions in adolescents. J Neurotrauma 2013;30:1469-75.

53 Iverson GL, Silverberg ND, Mannix R, et al. Factors associated with concussion-like symptom reporting in high school athletes. JAMA Pediatr 2015;169:1132-40.

54 Brooks BL, Mannix R, Maxwell B, et al. Multiple past concussions in high school football players. Am J Sports Med 2016;44:3243-51.

55 Howell DR, Beasley M, Vopat L, et al. The effect of prior concussion history on Dualtask gait following a concussion. J Neurotrauma 2017;34:838-44.

56 Merritt VC, Padgett CR, Jak AJ. A systematic review of sex differences in concussion outcome: what do we know? Clin Neuropsychol 2019;33:1016-43.

57 Trinh LN, Brown SM, Mulcahey MK. The influence of psychological factors on the incidence and severity of sports-related concussions: a systematic review. Am J Sports Med 2020;48:1516-25

58 Mollayeva T, El-Khechen-Richandi G, Colantonio A. Sex \& gender considerations in concussion research. Concussion 2018;3:CNC51.

59 Iverson GL, Gardner AJ, Terry DP, et al. Predictors of clinical recovery from concussion: a systematic review. Br J Sports Med 2017:51:941-8.

60 Eckner JT, O'Connor KL, Broglio SP, et al. Comparison of head impact exposure between male and female high school ice hockey athletes. Am J Sports Med 2018;46:2253-62

61 Kroshus E, Baugh CM, Stein CJ, et al. Concussion reporting, sex, and conformity to traditional gender norms in young adults. J Adolesc 2017;54:110-9.

62 Wunderle K, Hoeger KM, Wasserman E, et al. Menstrual phase as predictor of outcome after mild traumatic brain injury in women. $J$ Head Trauma Rehabil 2014;29:E1-8.

63 Zemek RL, Grool AM, Rodriguez Duque D, et al. Annual and seasonal trends in ambulatory visits for pediatric concussion in Ontario between 2003 and 2013. J Pediatr 2017;181:222-8.

64 Anzalone AJ, Blueitt D, Case T, et al. A positive Vestibular/Ocular motor screening (VOMS) is associated with increased recovery time after sports-related concussion in youth and adolescent athletes. Am J Sports Med 2017;45:474-9.

65 Master CL, Master SR, Wiebe DJ, et al. Vision and vestibular system dysfunction predicts prolonged concussion recovery in children. Clin J Sport Med 2018;28:139-45

66 Giza CC, Hovda DA. The new neurometabolic cascade of concussion. Neurosurgery 2014;75:\$24-33.

67 Barkhoudarian G, Hovda DA, Giza CC. The molecular pathophysiology of concussive brain injury. Clin Sports Med 2011;30:33-48.

68 Carman AJ, Ferguson R, Cantu R, et al. Expert consensus document: mind the gapsadvancing research into short-term and long-term neuropsychological outcomes of youth sports-related concussions. Nat Rev Neurol 2015;11:230-44.

69 Prins ML, Giza CC. Repeat traumatic brain injury in the developing brain. Int J Dev Neurosci 2012:30:185-90.

70 Schneider KJ, Meeuwisse WH, Nettel-Aguirre A, et al. Cervicovestibular rehabilitation in sport-related concussion: a randomised controlled trial. Br J Sports Med 2014;48:1294-8

71 Hislop MD, Stokes KA, Williams S, et al. Reducing musculoskeletal injury and concussion risk in schoolboy rugby players with a pre-activity movement control exercise programme: a cluster randomised controlled trial. Br J Sports Med 2017:51:1140-6.

72 Chang B-H, Hoaglin DC. Meta-analysis of odds ratios. Med Care 2017:55:328-35.

73 Daneshvar D, Nowinski C, McKee A, et al. The epidemiology of sport-related concussion. Clin J Sport Med 2012;30:1-17.

74 McCrea M, Meier T, Huber D, et al. Role of advanced neuroimaging, fluid biomarkers and genetic testing in the assessment of sport-related concussion: a systematic review. Br J Sports Med 2017:51:919-29. 